\title{
Psychosocial Effects of Physical and Verbal Abuse in Postmenopausal Women
}

\author{
Charles P. Mouton, MD, MS \\ Rebecca J. Rodabough, MS \\ Susan L. D. Rovi, PbD \\ Robert G. Brzyski, MD, PbD \\ David A. Katerndabl, MD, $M A^{4}$ \\ 'Department of Community and Family \\ Medicine, Howard University College of \\ Medicine, Washington, DC
}

${ }^{2}$ Fred Hutchinson Cancer Center, University of Washington School of Medicine, Seattle, Washington

${ }^{3}$ Department of Family Medicine, University of Medicine and Dentistry of New Jersey-New Jersey Medical School, Newark, New Jersey

${ }^{4}$ Department of Family and Community Medicine, University of Texas Health Science Center at San Antonio, San Antonio, Texas

\section{Conflicts of interest: none reported}

\section{CORRESPONDING AUTHOR}

Charles P. Mouton, MD, MS

Department of Community and Family Medicine

Howard University College of Medicine 520 W St, NW Rm 2400

Washington, DC 20059

cmouton@howard.edu

\begin{abstract}
PURPOSE The purpose of this study was to examine the psychological effects of physical and verbal abuse in a cohort of older women.

METHODS This observational cohort study was conducted at 40 clinical sites nationwide that are part of the Women's Health Initiative (WHI) Observational Study. We surveyed 93,676 women aged 50 to 79 years using the mental health subscales and the combined mental component summary (MCS) score of the RAND Medical Outcomes Study 36-item instrument.
\end{abstract}

RESULTS At baseline, women reporting exposure to physical abuse only, verbal abuse only, or both physical and verbal abuse had a greater number of depressive symptoms $(1.6,1.6$, and 3 more symptoms, respectively) and lower MCS scores (4.6, 5.4, and 8.1 lower scores, respectively) than women not reporting abuse. Compared with women who had no exposure to abuse, women had a greater increase in the number of depressive symptoms when they reported a 3-year incident exposure to physical abuse only $(0.2 ; 95 \%$ confidence interval [CI], -0.21 to $0.60)$, verbal abuse only $(0.18 ; 95 \% \mathrm{Cl}, 0.11$ to 0.24$)$, or both physical and verbal abuse $(0.15 ; 95 \% \mathrm{Cl},-0.05$ to 0.36$)$; and they had a decrease in MCS scores when they reported a 3 -year incident exposure to physical abuse only $(-1.12 ; 95 \% \mathrm{Cl}$, -2.45 to 0.12$)$, verbal abuse only $(-0.55 ; 95 \% \mathrm{Cl},-0.75$ to -0.34$)$, and both physical and verbal abuse $(-0.44 ; 95 \% \mathrm{Cl},-1.11$ to -0.22$)$ even after adjustment for sociodemographic characteristics.

CONCLUSION Exposure to abuse in older, functionally independent women is associated with poorer mental health. The persistence of these findings suggests that clinicians need to consider abuse exposure in their older female patients who have depressive symptoms. Clinicians caring for older women should identify women at risk for physical and verbal abuse and intervene appropriately.

Ann Fam Med 2010;8:206-213. doi:10.1370/afm.1095.

\section{INTRODUCTION}

1 buse is an ongoing concern for older women. ${ }^{1}$ Physical abuse is the infliction of physical pain, injury, or physical coercion, and involves at least 1 act of violence. Verbal abuse is the infliction of mental anguish through yelling, screaming, threatening, humiliating, infantilizing, or provoking intentional fear., ${ }^{1,2}$ Exposure to acts of abuse is a stressful event that has a negative effect on a woman's psychological well-being. It is known that in younger age-groups, domestic violence victims are at increased risk for psychological problems. ${ }^{3-5}$ Female victims are 2 times more likely to have a psychiatric diagnosis and 1.7 to 4.6 times more likely to develop an anxiety disorder, a mood disorder, posttraumatic stress disorder, or an eating disorder. ${ }^{6,7}$ Women exposed to abuse are more than 3 times as likely to report poor overall mental health, lower SF-12 Health Survey short-form mental component summary (MCS) scores, and lower vitality. ${ }^{3,7-10}$ Abused women are 2.4 to 3 times more likely to report depression. ${ }^{6,11-14}$ In addition to the direct psychological effects, abuse may negatively affect the factors that improve psychological well-being. ${ }^{14,15}$ 
Abuse is also a problem for older women. Fisher and Regan reported $47 \%$ of their sample of women older than 60 years reported abuse that occurred after age 55 years. ${ }^{16}$ In a community-based sample, Pillemer and Finkelhor showed the prevalence of abuse in older adults to be $3.2 \% .{ }^{17}$ In our previous work in more than 90,000 functionally independent older women from the Women's Health Initiative (WHI), we showed that $11.1 \%$ were abused in the past year, with a $5 \% 3$-year incidence among women not previously reporting abuse. ${ }^{18}$ Additional analyses from this large national sample showed that exposure to abuse was associated with being in the younger age cohort (younger than 58 years), being of nonwhite race/ethnicity, having less than high school education, having family incomes $\$ 20,000$ or less, being divorced or separated, being a past or current smoker, and drinking more than 1 drink per week (all $P$ values $\leq .01$ ). For older, functionally dependent adults, the prevalence of abuse ranges from approximately $1 \%$ for physical abuse to approximately $25 \%$ for psychological abuse. ${ }^{2,19}$

As with the younger population, abuse in older women is associated with poorer health outcomes. In a cohort of more than 150 older African American women, Paranjape et al showed that women exposed to abuse had worse SF-12 physical and mental component summary scores. ${ }^{10}$ We have also previously reported data from the WHI Observational Study showing that exposure to abuse affects an older woman's perceived physical health. ${ }^{20}$ Women exposed to emotional abuse had lower scores on physical functioning $(-6.91 ; 95 \%$ confidence interval $[\mathrm{CI}],-9.95$ to -3.86$)$ and general health $(-8.20 ; 95 \% \mathrm{CI},-10.92$ to -5.48$)$. We report on the mental health findings associated with abuse exposure from the WHI cohort of more than 93,000 older, functionally independent women.

To date, no study has examined the psychosocial effects of physical and verbal abuse in a large cohort of functionally independent, cognitively intact, older women. We hypothesized that late-life abuse is associated with mental health problems, and its impact is modified by social support and optimism. Physical abuse may have a greater effect on mental health than verbal abuse. The purpose of this study was twofold: (1) to examine the effects of abuse exposure at baseline on baseline mental health; and (2) to examine the change in mental health in postmenopausal women newly exposed to abuse during the 3-year follow-up period.

\section{METHODS}

\section{Subjects}

We analyzed survey responses from 93,676 women in the observational study arm of the WHI. The design of the WHI and its observations study arm has been described in detail previously. ${ }^{21}$ In brief, the WHI is a large, multicenter study of women, aged 50 to 79 years, with 2 components, an observational study and a clinical trial. All participants in the observational study arm completed questionnaires at enrollment, including questions about abuse. Three years after enrollment, participants had a follow-up clinic visit and completed similar questionnaires. The mean age was $65 \pm 9$ years, $83 \%$ were non-Hispanic white, $3.9 \%$ were Hispanic, $8.2 \%$ were African American, and $4.7 \%$ were from other or unknown racial or ethnic groups. Forty percent had incomes in excess of $\$ 50,000$, and $62 \%$ were married.

\section{Definition of Abuse Variables}

To determine the occurrence of physical abuse, the following standard screening question was asked: "Over the past year, were you physically abused by being hit, slapped, pushed, shoved, punched or threatened with a weapon by a family member or close friend?" To assess the severity of reported abuse, participants chose from the following responses: (1) no no $_{i}(2)$ yes, and it upset me not too much; (3) yes, and it upset me moderately; or (4) yes, and it upset me very much. To determine the occurrence of verbal abuse, the following standard question was asked: "Over the past year, were you verbally abused by being made fun of, severely criticized, told you were a stupid or worthless person, or threatened with harm to yourself, your possessions, or your pets by a family member or close friend? Participants chose from the following responses: (1) no ${ }_{i}(2)$ yes, and it upset me not too much; (3) yes, and it upset me moderately; or (4) yes, and it upset me very much. To determine the 3-year incidence of abuse in women who had no abuse exposure at baseline, we asked these same questions at their 3-year follow-up visit.

Any woman who indicated to clinic staff that she had been exposed to physical or verbal abuse was encouraged to use the Domestic Violence hotline, given information about domestic violence and the nearest battered women's shelter, and urged to seek help from Adult Protective Services and receive psychological counseling for domestic violence.

The baseline and follow-up abuse variables were our main predictor variables. Other predictor variables included age, race/ethnicity, occupation, marital status, household income, education, smoking history, alcohol intake, and living arrangement. These variables were chosen based on previous literature suggesting an association of sociodemographic characteristics (age, race/ethnicity, education, occupation, and income) and health behaviors (smoking and alcohol use) with elder abuse and intimate partner violence, as well as depressive symptoms and overall mental health. 


\section{Outcome Variables}

Overall mental health was assessed using the 36 questions from the RAND 36-Item Health Survey $1.0^{22}$ (RAND 36). The RAND 36 has 2 component summary scores made up of 8 subscales. We used the mental component summary score (MCS) as our main measure of overall mental health. The component summary scores range from 0 to 100 , with a mean of 50 and standard deviation of 10 . Higher scores indicate better mental health. Details of the reliability and predictive ability of this instrument have been described previously. ${ }^{23}$

Depressive symptomatology was assessed with a 6 -item version of the Center for Epidemiological Studies Depression Scale. ${ }^{24}$ Participants responded to the following items: (1) you felt depressed, (2) your sleep was restless, (3) you enjoyed life, (4) you had crying spells, (5) you felt sad, and (6) you felt people disliked you. Participants rated the frequency of these depressive symptoms during the past week as rarely, some or a little of the time, occasionally, or most of the time. Total scores could range from 0 to 18 . Higher scores indicate greater depressive symptomatology.

Social support was measured with 9 items from the Medical Outcomes Study Social Support Survey, ${ }^{22}$ a widely used and validated instrument, and scores could range from 9 to 45 , with higher scores indicating greater social support. Social strain (negative social support) was derived from 4 items that were part of a scale measuring negative aspects of social relations, with higher score indicating greater social strain. ${ }^{25,26} \mathrm{Opti}$ mism was derived from the revised Life Orientation Test. It consists of 65 -point response items with higher scores indicating greater optimism about the future. ${ }^{27}$

Because social support, social strain, and optimism were measured only at baseline, our main dependent variables at 3-year follow-up were depressive symptomatology and the MCS scale. We calculated the change in score from baseline for the depressive symptomatology scale and the MCS score, which became our main dependent variables at follow-up.

\section{Statistical Methods}

We examined descriptive statistics of each variable at baseline. We also examined the baseline and 3-year change from baseline of the depressive symptomatology score and the MCS score by the categories of physical and verbal abuse exposure. We used simple linear regression to perform tests for trends to assess the bivariate associations of increasing levels of abuserelated distress (reported as being upset), comparing each measure at baseline with differences in measures at a 3 -year follow-up. There was no significant trend noted for increasing levels of distress; thus, the responses were dichotomized as no or yes. These responses determined 4 mutually exclusive categories (no abuse, physical abuse only, verbal abuse only, and both physical and verbal abuse) at baseline and at 3year follow-up. At baseline and 3-year follow-up, $t$ tests from the simple linear regression models were used to test the association of each category of abuse at baseline with each of our outcome measures vs women reporting no abuse, unadjusted for any other factors.

To examine multiple dependent variables and control for type 1 error, we used multivariate analysis of variance (MANOVA) to assess for an association of new reports of the 3 abuse categories with changes in depressive symptomatology and the overall MCS score, controlling for other independent predictors. Overall $P$ values assessing the effect of a predictor variable on the dependent variables as a whole are reported from $\mathrm{Wilks}^{\prime} \lambda$ statistics. Complete case analysis was used for all modeling, and the data set was restricted to women with no report of abuse at baseline for this follow-up analysis. All explanatory variables were kept in each model, regardless of statistical significance. Thus, slope estimates for each explanatory variable control for all other variables in the model. All analyses were performed using the SAS System for Windows, version 9.00 (SAS Institute, Cary, North Carolina).

\section{RESULTS}

Of the 93,676 total WHI observational study participants, 93,025 responded to questions on abuse at baseline, and $11.1 \%$ reported exposure to some form of physical or verbal abuse (Table 1). Of the 10,389 women exposed to abuse, 225 (2.2\% of those abused) reported being exposed to physical abuse only, 9,239 (88.9\% of those abused) reported being exposed to verbal abuse only, and 925 (8.9\% of those abused) reported being both physically and verbally abused in the year before the baseline interview. At baseline, the mean RAND $36 \mathrm{MCS}$ score was 53.0.

When examining the association of abuse with each of our outcome variables at baseline, we found a greater number of depressive symptoms in abused women; the mean number of symptoms was greater than the recommended cutoff for major depression disorders in those exposed to both forms abuse. Similarly, social support and optimism scores were lower for abused women, and social strain was greater. Overall the MCS mental health scores were lower in association with abuse, with an 8-point lower score for exposure to both physical and verbal abuse. These findings represent a large and clinically significant association of abuse with more depressive symptoms and higher social strain, lower optimism, and lower MCS scores 


\begin{tabular}{|c|c|c|c|c|c|c|}
\hline Variable & N (\%) & $\begin{array}{c}\text { Depressive } \\
\text { Symptomatology } \\
\text { Mean (SD) }\end{array}$ & $\begin{array}{l}\text { MCS Score } \\
\text { Mean (SD) }\end{array}$ & $\begin{array}{l}\text { Social Support } \\
\text { Constructc } \\
\text { Mean (SD) }\end{array}$ & $\begin{array}{l}\text { Social Strain } \\
\text { Construct }^{\mathrm{d}} \\
\text { Mean (SD) }\end{array}$ & $\begin{array}{l}\text { Optimism } \\
\text { Construct }^{\mathrm{e}} \\
\text { Mean (SD) }\end{array}$ \\
\hline All & $93,676(100)$ & $2.4(2.6)$ & $53.0(8.5)$ & $35.9(7.9)$ & $6.5(2.5)$ & $23.3(3.5)$ \\
\hline \multicolumn{7}{|l|}{ Abuse } \\
\hline No abuse & $82,636(88.2)$ & $2.2(2.4)$ & $53.7(8.0)$ & $36.5(7.6)$ & $6.3(2.4)$ & $23.4(3.4)$ \\
\hline Physical abuse only & $225(0.2)$ & $3.8(3.4)$ & $49.1(11.0)$ & $33.2(8.6)$ & $7.5(3.0)$ & $21.8(3.8)$ \\
\hline Verbal abuse only & $9,239(9.9)$ & $3.8(3.3)$ & $48.3(10.3)$ & $31.9(8.4)$ & $8.2(2.8)$ & $22.2(3.8)$ \\
\hline $\begin{array}{l}\text { Physical and verbal } \\
\text { abuse }\end{array}$ & $925(1.0)$ & $5.2(4.0)$ & $45.6(11.5)$ & $29.6(9.4)$ & $8.9(3.4)$ & $21.4(3.9)$ \\
\hline \multicolumn{7}{|l|}{ Age, y } \\
\hline$\leq 58$ & $26,284(28.1)$ & $2.6(2.9)$ & $51.5(9.1)$ & $36.2(7.7)$ & $7.0(2.7)$ & $23.3(3.7)$ \\
\hline $59-64$ & $23,771(25.4)$ & $2.3(2.5)$ & $53.2(8.3)$ & $36.3(7.7)$ & $6.6(2.5)$ & $23.3(3.5)$ \\
\hline $65-69$ & $20,847(22.3)$ & $2.2(2.4)$ & $53.8(8.0)$ & $35.9(7.8)$ & $6.3(2.4)$ & $23.3(3.4)$ \\
\hline $70-74$ & $15,655(16.7)$ & $2.3(2.4)$ & $54.0(8.1)$ & $35.3(8.1)$ & $6.1(2.3)$ & $23.2(3.3)$ \\
\hline$>74$ & $7,119(7.6)$ & $2.3(2.3)$ & $54.2(8.2)$ & $34.7(8.4)$ & $5.9(2.3)$ & $23.0(3.3)$ \\
\hline \multicolumn{7}{|l|}{ Ethnicity } \\
\hline $\begin{array}{l}\text { American Indian/ } \\
\text { Alaskan Native }\end{array}$ & $422(0.5)$ & $3.4(3.5)$ & $51.3(9.9)$ & $33.1(9.4)$ & $7.2(3.1)$ & $22.3(3.6)$ \\
\hline Asian/Pacific Islander & $2,671(2.9)$ & $1.8(2.2)$ & $54.0(7.6)$ & $35.6(7.7)$ & $6.3(2.6)$ & $22.1(3.1)$ \\
\hline Black/African American & $7,639(8.2)$ & $2.6(2.9)$ & $52.1(9.3)$ & $34.5(8.4)$ & $7.4(3.1)$ & $23.1(3.5)$ \\
\hline Hispanic/Latino & $3,623(3.9)$ & $3.5(3.4)$ & $50.6(10.0)$ & $33.3(9.3)$ & $7.4(3.1)$ & $22.1(3.6)$ \\
\hline White & $78,013(83.3)$ & $2.3(2.5)$ & $53.2(8.3)$ & $36.2(7.7)$ & $6.4(2.4)$ & $23.4(3.5)$ \\
\hline Unknown & $1,308(1.4)$ & $2.6(2.8)$ & $52.4(9.0)$ & $34.3(8.6)$ & $6.9(2.7)$ & $22.5(3.6)$ \\
\hline \multicolumn{7}{|l|}{ Education } \\
\hline $0-8 y$ & $1,560(1.7)$ & $3.7(3.4)$ & $49.3(10.0)$ & $32.3(9.7)$ & $7.6(3.3)$ & $20.9(3.4)$ \\
\hline $\begin{array}{l}\text { Some high school, high } \\
\text { school diploma/GED }\end{array}$ & $18,409(19.8)$ & $2.7(2.8)$ & $52.3(9.0)$ & $35.7(8.2)$ & $6.6(2.7)$ & $22.3(3.4)$ \\
\hline School after high school & $33,933(36.5)$ & $2.5(2.6)$ & $53.0(8.7)$ & $35.6(8.0)$ & $6.6(2.6)$ & $23.2(3.4)$ \\
\hline $\begin{array}{l}\text { College graduate or } \\
\text { higher }\end{array}$ & $39,002(42.0)$ & $2.1(2.4)$ & $53.6(7.9)$ & $36.4(7.4)$ & $6.3(2.4)$ & $23.9(3.4)$ \\
\hline \multicolumn{7}{|l|}{ Family income } \\
\hline$<\$ 20,000$ & $14,016(16.2)$ & $3.1(3.1)$ & $51.2(9.9)$ & $32.4(9.0)$ & $7.0(2.9)$ & $22.1(3.6)$ \\
\hline$\$ 20,000-\$ 34,999$ & $20,226(23.3)$ & $2.5(2.6)$ & $52.9(8.7)$ & $34.9(8.0)$ & $6.5(2.6)$ & $22.9(3.5)$ \\
\hline$\$ 35,000-\$ 49,999$ & $17,429(20.1)$ & $2.3(2.5)$ & $53.3(8.3)$ & $36.1(7.5)$ & $6.4(2.4)$ & $23.4(3.4)$ \\
\hline$\$ 50,000-\$ 74,999$ & $17,486(20.2)$ & $2.1(2.4)$ & $53.5(8.0)$ & $37.2(7.1)$ & $6.4(2.4)$ & $23.7(3.4)$ \\
\hline$\geq \$ 75,000$ & $17,608(20.3)$ & $2.0(2.2)$ & $53.9(7.5)$ & $38.4(6.5)$ & $6.3(2.3)$ & $24.2(3.3)$ \\
\hline \multicolumn{7}{|l|}{ Marital status } \\
\hline Never married & $4,390(4.7)$ & $2.4(2.6)$ & $52.8(8.7)$ & $32.9(8.2)$ & $6.6(2.6)$ & $22.9(3.6)$ \\
\hline Divorced/ separated & $14,727(15.8)$ & $2.8(2.9)$ & $51.6(9.6)$ & $32.4(8.4)$ & $6.8(2.7)$ & $23.1(3.8)$ \\
\hline Widowed & $16,290(17.5)$ & $2.6(2.7)$ & $52.9(8.7)$ & $33.0(8.3)$ & $6.3(2.5)$ & $22.9(3.5)$ \\
\hline Presently married & $57,805(62.0)$ & $2.2(2.4)$ & $53.5(8.1)$ & $37.9(6.9)$ & $6.5(2.5)$ & $23.4(3.4)$ \\
\hline \multicolumn{7}{|l|}{ Smoking } \\
\hline Never smoked & $47,023(50.9)$ & $2.3(2.5)$ & $53.3(8.3)$ & $36.2(7.8)$ & $6.4(2.5)$ & $23.3(3.5)$ \\
\hline Past smoker & $39,514(42.8)$ & $2.4(2.5)$ & $53.1(8.4)$ & $35.9(7.8)$ & $6.5(2.5)$ & $23.3(3.5)$ \\
\hline Current smoker & $5,791(6.3)$ & $2.9(3.0)$ & $50.7(9.9)$ & $34.1(8.6)$ & $7.1(2.9)$ & $22.6(3.7)$ \\
\hline \multicolumn{7}{|l|}{ Alcohol intake } \\
\hline Nondrinker & $10,477(11.3)$ & $2.4(2.7)$ & $53.3(8.6)$ & $35.6(8.4)$ & $6.5(2.7)$ & $22.8(3.5)$ \\
\hline Past drinker & $17,555(18.9)$ & $2.7(2.8)$ & $52.2(9.2)$ & $34.8(8.4)$ & $6.9(2.8)$ & $22.8(3.6)$ \\
\hline$<1$ Drink per week & $29,461(31.7)$ & $2.4(2.6)$ & $52.9(8.5)$ & $35.7(7.8)$ & $6.5(2.5)$ & $23.2(3.4)$ \\
\hline$\leq 7$ Drinks per week & $23,842(25.6)$ & $2.2(2.4)$ & $53.4(8.1)$ & $36.7(7.3)$ & $6.3(2.4)$ & $23.6(3.4)$ \\
\hline >7 Drinks per week & $11,709(12.6)$ & $2.2(2.3)$ & $53.8(7.8)$ & $37.0(7.3)$ & $6.2(2.3)$ & $23.8(3.4)$ \\
\hline \multicolumn{7}{|l|}{ Living alone } \\
\hline No & $68,307(73.5)$ & $2.3(2.5)$ & $53.2(8.3)$ & $37.2(7.3)$ & $6.5(2.5)$ & $23.3(3.4)$ \\
\hline Yes & $24,603(26.5)$ & $2.6(2.8)$ & $52.5(9.0)$ & $32.3(8.3)$ & $6.4(2.5)$ & $23.1(3.6)$ \\
\hline
\end{tabular}


(trend, $P<.001$ on all measures). As expected, age, education, and income were associated with moderately more favorable psychosocial scores, but the magnitude of these associations are less than the effects of exposure to both physical and verbal abuse.

Table 2 shows the change from baseline depressive symptoms and MCS scores at the 3-year follow-up, excluding women who had reported abuse exposure at baseline. Women in all categories of abuse showed worse mental health compared with women reporting no abuse. New exposure to physical abuse resulted in an increase in depressive symptoms and a decline in MCS scores; however, only the decline in MCS scores reached statistical significance. This limited statistical significance may be due to a lack of power to detect a difference given the smaller subset of women reporting incident (new) exposure to physical abuse only. Women newly exposed to verbal abuse or to both physical and verbal abuse had an increase in depressive symptoms and a decline in MCS scores. The proportion of women newly reporting various categories of abuse showed small, statistically significant effects of verbal or combined verbal and physical abuse on the change in MCS and depression scores.

Table 3 displays the changes in MCS scores at the 3-year follow-up by category of abuse, controlling for our baseline psychosocial measures, age, race/ethnicity, education level, household income, occupation, marital status, smoking history, alcohol use, and living arrangement at baseline. Exposure to abuse was associated with worse scores at the 3-year follow-up on all our mental health outcomes. In this multivariate analysis, incident abuse and baseline measures of social support and optimism each remain independent, statistically significant predictors of changes in depressive symptoms and overall mental health at 3-year follow-up. Interestingly, changes in scores by category of abuse were not consistent across all psychosocial measures. Decline in the overall MCS scores for women exposed to abuse was greater than the changes associated with many of our other predictor variables (age, race/ethnicity, education, martial status, alcohol use, religious comfort, and living alone).

\section{DISCUSSION}

In this cohort of postmenopausal women, we found a relationship between exposure to abuse and poorer psychological health. At baseline, abused postmenopausal women had lower scores (45.6 vs 53.7 ) on the RAND $36 \mathrm{MCS}$ scale, greater depressive symptomatology, greater social strain and lower optimism compared with nonabused postmenopausal women. At follow-up 3 years later, postmenopausal women who did not report abuse at baseline but subsequently experienced abuse showed greater depressive symptoms and poorer MCS scores, even after controlling for baseline mental health. Also, our findings support previous research showing averse mental health outcomes in older women exposed to abuse, ${ }^{16}$ similar to what has been found for abused women in younger age-groups.

Interestingly, exposure to verbal abuse, even without physical abuse, had a strong effect on psychological health. This finding highlights the detrimental effects of verbal abuse on mental health, which is often unrecognized. In children, exposure to verbal abuse is associated with more disruptive behavior, greater psychological distress, and poorer social relationships. ${ }^{28}$ Sowell et al showed that verbal abuse had a significant negative correlation with self-confidence and self-esteem. ${ }^{29}$ In younger Pakistani women, verbal abuse was associated with an increased prevalence of anxiety and depression. ${ }^{30}$ In a review of psychological abuse, O'Leary shows that verbal abuse in spousal and long-term

relationships can have as great a psychological effect as physical abuse. ${ }^{31}$ Ours is the first report of the adverse mental health effects from verbal abuse in older women and suggest that greater attention needs to be paid to these effects.

The effect of verbal abuse on mental health may represent the effect of new strains in social relationships. Aging may affect social relationships by increasing disease burden, caregiving responsibilities, or fears of impeding dependency. Furthermore, verbal abuse typically represents a lower threat level than physical 
abuse and may encourage older women to remain in an abusive relationship longer.

These results also confirm earlier work showing diminished mental health associated with overall abuse in postmenopausal women. We previously found that $12.1 \%$ of women (aged 50 to 79 years) surveyed disclosed having experienced physical abuse, 28\% had been threatened with violence at some point in

Table 3. Multivariate Analysis of Variance Showing the Association of Change in Mental Health at Year 3 and Incident Abuse, Controlling for Baseline Psychosocial Characteristics

\begin{tabular}{|c|c|c|c|}
\hline Characteristic & $\begin{array}{l}\text { Change in No. of Depressive } \\
\text { Symptoms at 3-Year Follow-up } \\
\text { Parameter Estimate }(95 \% \mathrm{Cl})\end{array}$ & $\begin{array}{l}\text { Change in MCS Score } \\
\text { at 3-Year Follow-up } \\
\text { Parameter Estimate }(95 \% \mathrm{Cl})\end{array}$ & $\begin{array}{l}\text { Overall } \\
P \text { Value }\end{array}$ \\
\hline \multicolumn{4}{|l|}{ Abuse } \\
\hline \multicolumn{4}{|l|}{ Incident abuse (vs no abuse) } \\
\hline Physical abuse only ( $n=136$ ) & $0.20(-0.21$ to 0.60$)$ & $-1.12(-2.45$ to 0.21$)$ & .006 \\
\hline Verbal abuse only $(n=6,133)$ & 0.18 (0.11 to 0.24$)$ & $-0.55(-0.75$ to -0.34$)$ & $<.001$ \\
\hline Physical and verbal abuse $(n=483)$ & $0.15(-0.05$ to 0.36$)$ & $-0.44(-1.11$ to -0.22$)$ & $<.001$ \\
\hline \multicolumn{4}{|l|}{ Baseline psychosocial characteristics } \\
\hline Depressive symptoms & & $-0.20(-0.23$ to -0.16$)$ & $<.001$ \\
\hline MCS score & 0.06 (0.05 to 0.06$)$ & & $<.001$ \\
\hline Social support & $-0.01(-0.01$ to -0.01$)$ & 0.05 (0.04 to 0.06$)$ & $<.001$ \\
\hline Social strain & 0.07 (0.06 to 0.08$)$ & $-0.24(-0.27$ to -0.22$)$ & $<.001$ \\
\hline Optimism & $-0.04(-0.05$ to -0.04$)$ & $0.16(0.14$ to 0.18$)$ & $<.001$ \\
\hline \multicolumn{4}{|l|}{ Demographic characteristics } \\
\hline \multicolumn{4}{|l|}{ Age, years (vs 50-58 years) } \\
\hline $59-64$ & $-0.08(-0.13$ to -0.03$)$ & 0.59 (0.44 to 0.74$)$ & $<.001$ \\
\hline $65-69$ & $-0.07(-0.12$ to -0.02$)$ & $0.61(0.45$ to 0.77$)$ & $<.001$ \\
\hline $70-79$ & $0.01(-0.05$ to 0.06$)$ & $0.41(0.23$ to 0.60$)$ & $<.001$ \\
\hline \multicolumn{4}{|l|}{ Race (vs non-Hispanic Whites) } \\
\hline American Indian & $-0.05(-0.13$ to 0.03$)$ & $0.10(-0.16$ to 0.36$)$ & $<.001$ \\
\hline Asian/Pacific Islander & 0.22 (0.11 to 0.33$)$ & $-0.24(-0.61$ to 0.13$)$ & $<.001$ \\
\hline African American & $0.19(-0.11$ to 0.49$)$ & $-0.29(-1.29$ to 0.71$)$ & .005 \\
\hline Hispanic American & $-0.36(-0.46$ to -0.25$)$ & $-0.08(-0.42$ to 0.27$)$ & $<.001$ \\
\hline Unknown & 0.24 (0.08 to 0.40$)$ & $-0.44(-0.96$ to 0.09$)$ & $<.001$ \\
\hline \multicolumn{4}{|l|}{ Education (vs college graduate) } \\
\hline High school diploma or less & 0.06 (0.01 to 0.12$)$ & 0.27 (0.08 to 0.46$)$ & $<.001$ \\
\hline Some college/technical school & 0.08 (0.04 to 0.13$)$ & $0.07(-0.08$ to 0.22$)$ & $<.001$ \\
\hline \multicolumn{4}{|l|}{ Income (vs $\$ 75,000+$ ) } \\
\hline$<\$ 20,000$ & $0.22(0.14$ to 0.29$)$ & $-0.67(-0.92$ to -0.42$)$ & $<.001$ \\
\hline$\$ 20,000-\$ 34,999$ & 0.13 (0.07 to 0.19$)$ & $-0.52(-0.72$ to -0.32$)$ & $<.001$ \\
\hline$\$ 35,000-\$ 49,999$ & 0.07 (0.01 to 0.13$)$ & $-0.16(-0.35$ to 0.03$)$ & $<.001$ \\
\hline$\$ 50,000-\$ 74,999$ & $0.03(-0.02$ to 0.09$)$ & $-0.12(-0.30$ to 0.06$)$ & $<.001$ \\
\hline \multicolumn{4}{|l|}{ Marital status (vs presently married) } \\
\hline Never married & $-0.11(-0.20$ to -0.01$)$ & 0.32 (0.00 to 0.64$)$ & $<.001$ \\
\hline Divorced & $-0.06(-0.13$ to 0.01$)$ & $0.13(-0.10$ to 0.37$)$ & $<.001$ \\
\hline Widowed & $-0.22(-0.29$ to -0.15$)$ & 0.99 (0.75 to 1.22$)$ & $<.001$ \\
\hline \multicolumn{4}{|l|}{ Smoking status (vs never smoked) } \\
\hline Past smoker & $0.06(0.02$ to 0.10$)$ & $-0.05(-0.17$ to 0.08$)$ & $<.001$ \\
\hline Current smoker & $0.22(0.14$ to 0.30$)$ & $-1.06(-1.32$ to -0.80$)$ & $<.001$ \\
\hline \multicolumn{4}{|l|}{ Alcohol use (vs past or never drank) } \\
\hline$<1$ Drink per week & $-0.04(-0.90$ to 0.01$)$ & $0.07(-0.08$ to 0.23$)$ & $<.001$ \\
\hline$\geq 1$ Drink per week & $-0.04(-0.09$ to 0.00$)$ & $0.04(-0.12$ to 0.19$)$ & $<.001$ \\
\hline \multicolumn{4}{|l|}{$\begin{array}{l}\text { How much does your religion comfort } \\
\text { you (vs little/none) }\end{array}$} \\
\hline A great deal & $-0.03(-0.07$ to 0.01$)$ & $0.12(-0.01$ to 0.25$)$ & $<.001$ \\
\hline \multicolumn{4}{|l|}{ Living alone (vs no) } \\
\hline Yes & $-0.06(-0.12$ to 0.00$)$ & 0.25 (0.04 to 0.46$)$ & .005 \\
\hline
\end{tabular}


their life, and $4.3 \%$ were currently in a relationship in which they had been threatened. ${ }^{32}$ In the current study, women who experienced threats of abuse had average MCS scores of 49.7 compared with 53.6 for those who had not experienced threats of abuse $(P$ value $=.002$ ). This 3.9 difference in scores is similar to the difference in MCS scores for patients with a new onset of neuropathic pain. ${ }^{33}$ For depressive symptoms at baseline, women who experienced physical and verbal abuse had 5.2 symptoms compared with 2.2 for women who were not abused. A cutoff score of 5 has a sensitivity of $80 \%$ and specificity of $84 \%$ for clinical depression. ${ }^{34}$ Our findings show that negative mental health effects persist despite controlling for optimism and social support.

Our study has some limitations, however. First, the women in our sample were volunteers for the WHI clinical trial and had higher education and higher incomes than the postmenopausal population generally. Second, categorization of physical abuse, verbal abuse, and the combined group relies on self-reports of victimization. Women may have been reluctant to admit being abused, resulting in an underestimate of exposure. Finally, data on optimism, social strain, and social support were not collected at follow-up. Thus, we are unable to examine the change in these constructs in women who have an incident exposure to abuse.

Despite these limitations, our findings that postmenopausal women exposed to abuse have poorer psychological health across a range of measures have important implications. Late-life domestic violence in older relationships adversely affects important psychological dimensions that contribute to a good quality of life. Even in this cohort of well-functioning postmenopausal women, physical and verbal abuse exposure have greater adverse effects on psychological wellbeing than sociodemographic factors. Furthermore, verbal abuse only had greater effects than physical abuse only. These results suggest that detecting and alleviating abusive situations may have important beneficial effects on the mental health and overall quality of life of older women. Our findings also suggest the need to educate the public, particularly older adults, about the adverse effects of verbal abuse. Clinicians should consider providing counseling and support services for these older victims to mitigate the adverse mental health effects of abuse.

To read or post commentaries in response to this article, see it online at http://www.annfammed.org/cgi/content/full/8/3/206.

Key words: Elder abuse; women's health; mental health; health status

Submitted December 9, 2008; submitted, revised, September 29, 2009; accepted November 9, 2009.
Author contributions: Dr Mouton, as principal investigator on this study, takes full responsibility for the integrity of the data and the accuracy of the data analyses.

Charles P. Mouton: study concept and design, acquisition of participants or data, analysis and interpretation of results, drafting of manuscript, critical revision of the manuscript for important intellectual content.

Rebecca J. Rodabough: study concept and design, acquisition of participants or data, analysis and interpretation of results, drafting of manuscript, critical revision of the manuscript for important intellectual content.

Susan L. D. Rovi: study concept and design, analysis and interpretation of results, drafting of manuscript, critical revision of the manuscript for important intellectual content.

Robert G. Brzyski: acquisition of participants or data, critical revision of the manuscript for important intellectual content.

David A. Katerndahl: analysis and interpretation of results, drafting of manuscript, critical revision of the manuscript for important intellectual content

Funding support: This study was supported by National Institutes of Health grants KO8AG00822, HL 63293, and HL 07575.

Acknowledgments: We acknowledge review of this manuscript by Margo Thombs.

\section{References}

1. Bonnie RJ, Wallace RB, eds. National Research Council, Committee on National Statistics and Committee on Law and Justice, Division of Behavioral and Social Sciences and Education. Elder Mistreatment. Abuse, Neglect, and Exploitation in an Aging America. Washington, DC: The National Academies Press; 2003.

2. The National Center on Elder Abuse. The National Elder Abuse Incidence Study. Final Report. Washington, DC: Administration for Children and Families and the Administration on Aging, DHHS; 1998.

3. Lown EA, Vega WA. Intimate partner violence and health: selfassessed health, chronic health, and somatic symptoms among Mexican American women. Psychosom Med. 2001;63(3):352-360.

4. Edwards VJ, Black MC, Dhingra S, McKnight-Eily L, Perry GS. Physical and sexual intimate partner violence and reported serious psychological distress in the 2007 BRFSS. Int J Public Health. 2009;54(Suppl 1):37-42.

5. Afifi TO, MacMillan H, Cox BJ, Asmundson GJ, Stein MB, Sareen J. Mental health correlates of intimate partner violence in marital relationships in a nationally representative sample of males and females. J Interpers Violence. 2009;24(8):1398-1417.

6. Danielson KK, Moffitt TE, Caspi A, Silva PA. Comorbidity between abuse of an adult and DSM-III-R mental disorders: evidence from an epidemiological study. Am J Psychiatry. 1998;155(1):131-133.

7. Golding J. Intimate partner violence as a risk factor for mental disorders: a meta-analysis. J Fam Violence. 1999;14(2):99-132.

8. Wagner PJ, Mongan PF. Validating the concept of abuse: women's perceptions of defining behaviors and the effects of emotional abuse on health indicators. Arch Fam Med. 1998;7(1):25-29.

9. Straus H, Cerulli C, McNutt L, et al. Intimate partner violence and functional health status: associations with severity, danger, and self-advocacy behaviors. J Womens Health (Larchmt). 2009;18(5):625-631.

10. Paranjape A, Sprauve-Holmes N, Gaughan J, Kaslow N. Lifetime exposure to family violence: implications for the health status of older African American women. J Womens Health (Larchmt). 2009;18(2):171-175. 
11. Petersen R, Gazmararian J, Andersen Clark K. Partner violence: implications for health and community settings. Womens Health Issues. 2001;11(2):116-125.

12. Leserman J, Li Z, Drossman DA, Hu YJ. Selected symptoms associated with sexual and physical abuse history among female patients with gastrointestinal disorders: the impact on subsequent health care visits. Psychol Med. 1998;28(2):417-425.

13. Roberts GL, Williams GM, Lawrence JM, Raphael B. How does domestic violence affect women's mental health? Women Health. 1998;28(1):117-129.

14. Jaffe P, Wolfe DA, Wilson S, Zak L. Emotional and physical health problems of battered women. Can J Psychiatry. 1986;31(7):625-629.

15. Coker AL, Smith PH, Thompson MP, Mckeown RE, Bethea L, Davis KE. Social support protects against the negative effects of partner violence on mental health. J Womens Health Gend Based Med. 2002;11(5):465-476.

16. Fisher BS, Regan SL. The extent and frequency of abuse in the lives of older women and their relationship with health outcomes. Gerontologist. 2006;46(2):200-209.

17. Pillemer K, Finkelhor D. The prevalence of elder abuse: a random sample survey. Gerontologist. 1988;28(1):51-57.

18. Mouton CP, Rodabough RJ, Rovi SL, et al. Prevalence and 3-year incidence of abuse among postmenopausal women. Am J Public Health. 2004;94(4):605-612.

19. Cooper C, Selwood A, Livingston G. The prevalence of elder abuse and neglect: a systematic review. Age Ageing. 2008;37(2):151-160.

20. Mouton C. Intimate partner violence and health status among older women. Violence Against Women. 2003;9(12):1465-1477.

21. Gore MJ. The Women's Health Initiative: studying interventions over the long term. Clin Lab Sci. 1995;8(6):311-316.

22. Hays RD, Sherbourne CD, Mazel RM. The RAND 36-ltem Health Survey 1.0. Health Econ. 1993;2(3):217-227.

23. Ware JE Jr, Sherbourne CD. The MOS 36-item short-form health survey (SF-36). I. Conceptual framework and item selection. Med Care. $1992 ; 30(6): 473-483$.
24. Burnam MA, Wells KB, Leake B, Landsverk J. Development of a brief screening instrument for detecting depressive disorders. Med Care. 1988;26(8):775-789.

25. Antonucci T, Kahn R, Akiyama H. Psychosocial factors and the repsonse to cancer symptoms. In Yancik R, Yates J, eds. Cancer in the Elderly: Approaches to Early Detection and Treatment. New York, NY: Springer Press; 1989.

26. Vinokur A, van Ryn A. Social Support and undermining in close relationships: their independent effect on the mental health of unemployed persons. J Pers Soc Psychol. 1993;993(65):350-359.

27. Scheier MF, Carver CS, Bridges MW. Distinguishing optimism from neuroticism (and trait anxiety, self-mastery and self-esteem): a reevaluation of the life orientation test. J Pers Soc Psychol. 1994; 67(6):1063-1078

28. Edwards VJ, Holden GW, Felitti VJ, Anda RF. Relationship between multiple forms of childhood maltreatment and adult mental health in community respondents: results from the adverse childhood experiences study. Am J Psychiatry. 2003;160(8):1453-1460.

29. Sowell R, Seals B, Moneyham L, Guillory J, Mizuno Y. Experiences of violence in HIV-seropositive women in the south-eastern United States of America. J Adv Nurs. 1999;30(3):606-615.

30. Ali BS, Rahbar MH, Naeem S, Tareen AL, Gul A, Samad L. Prevalence of and factors associated with anxiety and depression among women in a lower middle class semi-urban community of Karachi, Pakistan. J Pak Med Assoc. 2002;52(11):513-517.

31. O'Leary KD. Psychological abuse: a variable deserving critical attention in domestic violence. Violence Vict. 1999;14(1):3-23.

32. Mouton CP, Rovi S, Furniss K, Lasser NL. The associations between health and domestic violence in older women: results of a pilot study. J Womens Health Gend Based Med. 1999;8(9):1173-1179.

33. Williams LS, Jones WJ, Shen J, Robinson RL, Weinberger M, Kroenke K. Prevalence and impact of depression and pain in neurology outpatients. J Neurol Neurosurg Psychiatry. 2003;74(11):1587-1589.

34. Santor DA, Coyne JC. Shortening the CES-D to improve its ability to detect cases of depression. Psychol Assess. 1997;9(3):233-243. 